\title{
Investigation of Reactive Oxygen Species production in Human Hepatocytes
}

\author{
Troy B. Puga ${ }^{1}$, Joshua Schafer ${ }^{1}$, Pearce Harris ${ }^{1}$, Gary Branum ${ }^{1}$, Nora Strasser ${ }^{1}$, Prince N. Agbedanu ${ }^{*}$ \\ ${ }^{1}$ Department of Health Sciences, Division of Science, Technology, Engineering, and Math, Friends University, Wichita, KS 67213, USA.
}

*Corresponding Author: Prince N. Agbedanu, Department of Health Sciences, Division of Science, Technology, Engineering, and Math, Friends University, Wichita, KS 67213, USA.

Received date: December 17, 2021; Accepted date: December 28, 2021; Published date: January 12, 2022

Citation: Troy B. Puga, Schafer J., Harris P., Branum G., Strasser N., Prince N. Agbedanu (2022), Investigation of Reactive Oxygen Species production in Human Hepatocytes. J. Gastroenterology Pancreatology and Hepatobilary Disorders. 6(2) DOI: 10.31579/2641-5194/058

Copyright: (C) 2022, Prince N. Agbedanu, This is an open access article distributed under the Creative Commons Attribution License, which permits unrestricted use, distribution, and reproduction in any medium, provided the original work is properly cited.

\section{Abstract:}

1. Aim/Background: Reactive oxygen species (ROS) have been identified as compounds responsible for producing cellular damage. The purpose of this research is to examine if there is production of reactive oxygen species through free radical intermediates within human hepatocytes treated with morphine, bilirubin, or furosemide. The investigation examines the early stages of biotransformation by measuring the levels of reactive oxygen species produced inside of the treated hepatocytes within the first and second hours of treatment. The experiment was designed upon a case of a jaundiced (elevated bilirubin) infant who received morphine and furosemide and later died through unknown mechanisms. The experiment looks to examine if these drug compounds could contribute to cellular damage. This can help to further understand the potential interactions and complications of free radical intermediates produced during the phases of biotransformation.

2. Method: Previously cultured human hepatocytes were washed by centrifugation and re-suspended in $1 \mathrm{x}$ supplemental buffer to a concentration of $1 \times 10^{6}$ cells $/ \mathrm{mL}$ and seeded in a dark clear bottom 96-well microplate at 100,000 stained cells/well. The cells were treated with either furosemide, morphine, bilirubin, a Tert-Butyl hydro peroxide (TBHP) positive control, or left as a background. Reactive oxygen generated in the presence of these agents were quantified by fluorescence excitation/emission measurement at $495 \mathrm{~nm} / 529 \mathrm{~nm}$. Fluorescence was measured at one and two hours. ROS generated convert 2',7'-dichlorodihydrofluorescein diacetate to 2',7'dichlorodihydrofluorescein within the cells, which fluoresces. The fluorescence intensity detected is equivalent to the level of ROS generated. Wells that were untreated were used as blanks and subtracted from background and TBPH.

3. Results: Furosemide and Morphine did not produce statistically significant levels of ROS ( $p>0.05)$ above the background in both hours 1 and 2 of biotransformation and ROS measurement (Figure 1). Although Bilirubin did not produce statistically significant ( $\mathrm{p}$ $>0.05$ ) levels of ROS above the background (Figure 2) during the first hour, it did produce statistically significant levels in the second hour of biotransformation. Each compound's level of ROS was reduced during the second hour, signaling the removal of intermediate ROS metabolites (Figure 2). The production of ROS in each compound signifies that there is biotransformation to an intermediate that produces ROS.

4. Conclusion: The production of ROS above the background by each of the compounds shows there is an intermediate free radical compound that is produced during the biotransformation of each compound [21]. In this study, although furosemide and morphine did not produce statistically significant levels of ROS in both hours of biotransformation, bilirubin did produce significant levels of ROS in the second hour of biotransformation. This finding is in line with previous studies that shows morphine to offer protective effects against ROS production [16, 17]; and bilirubin demonstrating deleterious production of ROS at high doses [18]. Further work must be done to examine the correlation between the levels of ROS and extent of hepatocellular damage.

Key words: jaundice; reactive oxygen species; furosemide; morphine; bilirubin; hepatocyte; 2',7'-dichlorodihydrofluorescein diacetate; dichlorodihy drofluorescein diacetate; dimethyl sulfoxide; tert-butyl hydro peroxide

\section{Abbreviations}

H2DCFDA: 2',7'-dichlorodihydrofluorescein diacetate

DFCDA: dichlorodihydrofluorescein diacetate
TBHP: Tert-Butyl Hydroperoxide

DMSO: dimethyl sulfoxide

PBS: Phosphate buffered saline 


\section{Introduction}

This investigation is based upon the story of a jaundiced infant who was administered furosemide and morphine (while on supplemental oxygen), and later died due to unknown mechanisms. The infant presented with high levels of bilirubin shortly after birth, noted through jaundice (yellowing of the skin and sclera). Jaundice occurs due to a build-up of bilirubin that is not metabolized through conjugation and excretion in the urine (urobilinogen) or stool (stercobilinogen) [1]. Bilirubin is conjugated by the enzyme UDP-Glucuronosyltransferase within hepatocytes [1]. It is common for neonates to have elevated levels of bilirubin through physiologic neonatal jaundice, due to low levels of the enzyme UDPGlucuronosyltransferase at the beginning of life [2]. As the patient's condition became severe, it became necessary under the Physician's determination to provide supplemental oxygen, furosemide, and morphine.

Many xenobiotics have been shown to undergo biotransformation in the liver through a two-phase transformation. Phase 1 typically involves the processing of the xenobiotic through the CYP450 family of enzymes. Phase 2 typically involves the conjugation, sulfonation, or acetylation of the xenobiotic intermediate [3] although, these phases can occur out of order. The purpose of biotransformation is to deactivate potentially toxic substances within the body [3]. Biotransformation can also transform compounds into a toxic form [3]. Production of a toxic intermediate can affect the body and is dependent on several factors, such as how quickly it can be metabolized to a less toxic compound [3]. The free radical intermediates may produce Reactive Oxygen Species (ROS). ROS are unstable molecules composed of oxygen free radicals that can produce numerous random reactions [4]. ROS is formed in mitochondria as a sideproduct of the electron transport chain [5]. At low, biological levels, ROS is involved in immune protection and cell signalling [6]. Many life forms, including mitochondria, protect themselves from the toxic effects of ROS by utilizing antioxidants [7]. When ROS production in cells exceeds biological limits, it is capable of damaging macromolecules and causing cell death [8]. This experiment investigates the levels of ROS produced in the presence of furosemide, morphine, and bilirubin. The study will examine the biotransformation of each compound to determine if there is production of free radical intermediates that may produce cellular damage.

Materials and Method

\section{Buffers}

Fetal Bovine Serum ( $2 \mathrm{ml}$ ) was added to $18 \mathrm{~mL}$ of $1 \mathrm{x}$ PBS buffer to create a supplemental buffer. A 20 micromolar solution of 2',7'dichlorodihydrofluorescein diacetate (H2DCFDA) was prepared by adding 2.5 microliters of $20 \mathrm{mM}$ of dichlorodihydrofluorescein diacetate (DFCDA) in dimethyl sulfoxide (DMSO) to $2.5 \mathrm{~mL}$ solution of a previously prepared 1x PBS buffer [10]. In addition, a tert-Butyl hydroperoxide (TBHP) solution was prepared as a positive control, by adding 4.5 microliters of $55 \mathrm{mM}$ TBHP to $2.5 \mathrm{~mL}$ of $1 \mathrm{x}$ supplemental buffer, yielding a 100 micromolar solution [10].

\section{ROS Detection Assay}

ROS production was detected using the DCFDA/H2DCFDA - Cellular ROS Assay Kit (ab113851) by abcam [10]. Human Suspension Hepatocytes (Gibco $^{\text {TM }}$ Human Suspension Hepatocytes, Metabolism Qualified) were maintained in William's Medium E (Gibco, A1217601) in the presence of $4 \% \mathrm{CO}_{2}$ and media changed at 48 -hour intervals. The media was supplemented with the Gibco Primary Hepatocyte Maintenance Supplements (Gibco CM4000). The cultured cell suspensions were washed by centrifugation in phosphate buffer solution [10]. The cells were stained with the DCFDA solution at a concentration of $1 \times 10^{6}$ cells $/ \mathrm{mL}$ and incubated at 37 degrees Celsius for 30 minutes in the dark. The cells were washed by centrifugation with $1 \mathrm{x}$ buffer to remove excess dye. The washed cells were re-suspended in $1 \mathrm{x}$ supplemental buffer to a concentration of $1 \times 10^{6}$ cells $/ \mathrm{mL}$ and seeded in a dark clear bottom 96-well microplate at 100,000 stained cells/well. The cells were treated with furosemide, morphine, bilirubin, a TBPH positive control, or left as a background. Reactive oxygen generated in the presence of these agents were quantified by fluorescence excitation/emission measurement at $495 \mathrm{~nm} / 529 \mathrm{~nm}$. ROS generated convert 2',7'-dichlorodihydrofluorescein diacetate to 2',7'dichlorodihydrofluorescein within the cells which fluoresces. The fluorescence intensity detected is equivalent to the level of ROS generated. Fluorescence was measured at one and two hours. Wells untreated were measured as blanks and subtracted from background and TBPH [10].

\section{Data analysis}

An unpaired t-test (Suppl. Table 1.) was performed to compare the means of each of the compounds to the background to test for significance at hours 1 and 2 .

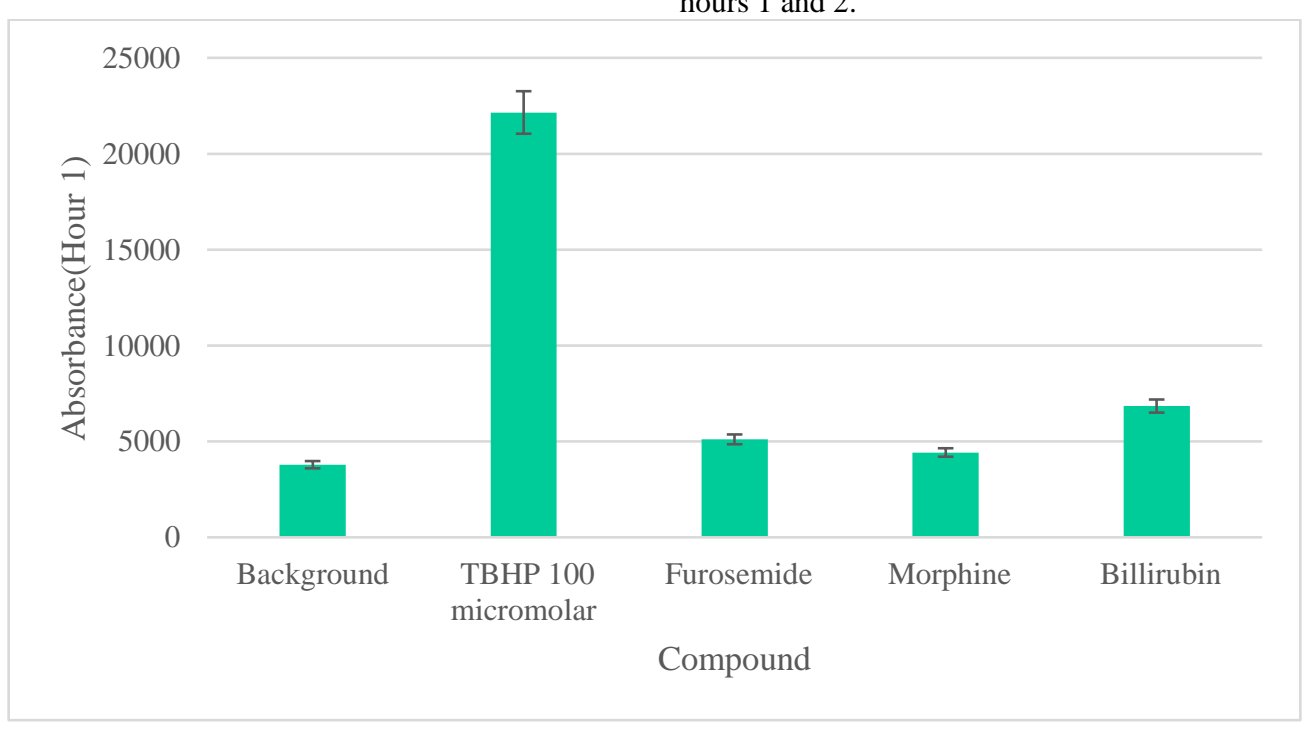

Figure 1: Reactive Oxygen Species levels measured one hour after incubation of cells with a background, positive control (TBHP), Furosemide, Morphine or Bilirubin. 


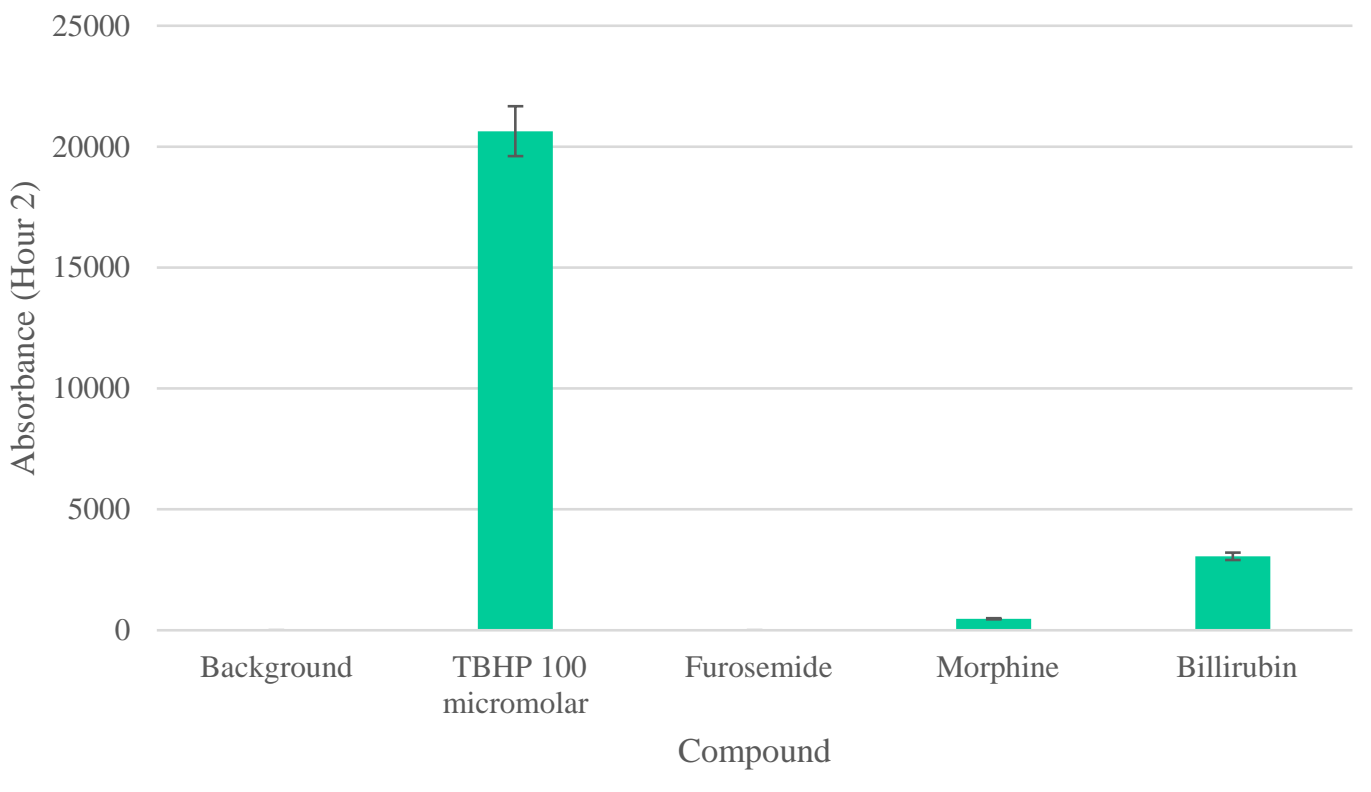

Figure 2: Reactive Oxygen Species levels measured two hours after incubation of cells with a background, positive control (TBHP), Furosemide, Morphine or Bilirubin.

\section{Results}

Furosemide, Morphine, or Bilirubin did not produce statistically significant levels of ROS ( $p>0.05)$ above the background within the first hour of biotransformation (Figure 1). ROS due to Furosemide was completely depleted in the second hour. Morphine did not produce statistically significant $(p>0.05$ ) levels of ROS during the second hour above the background (Figure 2). ROS levels from Bilirubin in the second hour, however, were found to be statistically significant. ROS produced by each compound was depleted to various degrees in the second hour, suggesting the removal of intermediate ROS metabolites (Figure 2). The production of ROS in each compound also signifies that there was biotransformation to an intermediate that produces ROS [21].

\section{Discussion}

Furosemide is a diuretic use to treat hypertension, with a unique sparing effect on the clearance of potassium [11], by blocking $\mathrm{Na}+, \mathrm{K}+, 2 \mathrm{Cl}-$ cotransporter (NKCC2) in the thick ascending limb (TAL) of the loop of Henle [12,13]. Despite its sparing effects on potassium, furosemide is known to induce a compartmentalized oxidative stress in hepatic mitochondria [14]. In this study, we have used whole liver cells without isolating mitochondria. We aim to mimic physiological conditions as much as possible, although there is still a limitation to the use of liver cells in assays, such as this type. The low levels of ROS detected due to furosemide may be attributable to the cellular environmental differences compared to organelle compartments (e.g., the mitochondria). Previous studies have shown that mitochondria is a key source of ROS production [19], hence, ROS levels in the mitochondria and its surroundings may be higher compared to remote areas in whole cells [22]. However, given our goal to mimic physiological conditions of the subject in question, we have used whole liver cells, as opposed to isolated mitochondria.

At low concentration, morphine is found to have promoted cell proliferation and suppressed nicotine-induced cell death in PC12 cells $[15,16]$. It was also demonstrated to have neuroprotective roles in Parkinson's disease models by the improvement of mitochondrial function via the inhibition of ROS production [16, 17]. Although furosemide has the potential to induce ROS, morphine has been shown to inhibit oxidative stress via the improvement of mitochondrial function. This antagonistic effect of morphine on ROS generation [16, 17] explain the very low and insignificant levels of ROS detected compared to background (Figure 1).

The detection of ROS above background levels in our experiments suggests the production of an intermediate compound-endogenous highly reactive oxygen-bearing molecule [20] during biotransformation. However, the insignificant levels of free radical intermediate due to furosemide, and the possible antagonistic effect of morphine on ROS production [16, 17] by furosemide, may not have allowed high enough levels of ROS in the subject to induce cellular damage.

At low doses, bilirubin in its unconjugated form has antioxidant effects, but at high doses produces deleterious neurological damage and death due to oxidative stress [18]. Although ROS detected due to bilirubin was also insignificant in the first hour, ROS levels due to bilirubin were statistically significant in the second hour (Figure 1, Suppl. Table 1) and clinically may be implicated in cell death [23]. Based on our data, we can safely rule out significant ROS production due to furosemide and morphine (Figure 1).

The biologically tolerable levels of bilirubin have been documented to be as high as $12.9 \mathrm{mg} / \mathrm{dL}$ among newborns [22]. Our results suggest that 100 micromolar $(1.131 \mathrm{mg} / \mathrm{dL})$ of bilirubin could induce the production of significant levels of ROS within two hours in hepatocytes, in vitro. This result from a direct cellular exposure to biliubin in vitro, an outcome which may be different from whole body exposure and that explains why the body tolerates as high as $12.9 \mathrm{mg} / \mathrm{dL}$ [22]. Nonetheless, the damaging effect of jaundice are known to be cumulative [24]. Although the body's homeostasis may allow it to tolerate such levels, the cumulative effects may not be immediately obvious.

\section{Conclusion}

We have not performed cell death assays to determine the possibility of hepatocellular damage due to these compounds in isolation. We aimed to determine the production of ROS in the presence of furosemide, morphine and bilirubin. We found the levels of ROS produced due to furosemide and morphine in both hours of biotransformation were statistically 
insignificant compared to background levels of ROS. We found the level of ROS produced due to bilirubin in the second hour of biotransformation to be statistically significant. Based on the level of ROS production, we conclude that cell death may be likely due to bilirubin and less likely due to furosemide or morphine. The minimum level of free radical accumulation needed to cause cellular damage due to bilirubin, especially, must be further investigated along with cell death assays.

\section{Limitations of study}

The experiments were performed in vitro rather than in vivo. There could be potential differences in the effects of the compounds in vivo. Further investigation could not be performed at this time due to budget constraints. We encourage other researchers to continue investigations into these compounds in vivo to explore these possibilities.

\section{Further hypothesis}

Further work must be done to examine the correlation between the levels of ROS and the extent of cell damage.

\section{Acknowledgment}

We thank the Friends University VPAA office, and the division Chair, Dr. Nora Strasser, for the provision of starter funds to support research involving undergraduates. We thank Ms. Amy Morgan for the procurement of equipment and materials needed to execute all projects.

\section{Author Contribution}

G.B. conceived the project. P.N.A, T.P, J.S. and P.H. designed the experiments. T.P., J.S., and P.H. performed all experiments. T.P. and N.S. analyzed the data. T.P. wrote the manuscript. P.N.A. and G.B. edited and proofread the manuscript. P.N.A. procured funding.

\section{Conflicts of Interest}

The authors of this article do not have any conflicts of interest regarding this research. The authors did not discriminate any participants or aspects of research based on race, gender, or religion.

\section{References:}

1. Kalakonda, A., Jenkins, B. A., \& John, S. (2021). Physiology, Bilirubin. 2021 Sep 16. In StatPearls [Internet]. StatPearls Publishing; Treasure Island (FL): StatPearls Publishing; 2021 Jan-. PMID: 29261920

2. Ansong-Assoku B, Ankola PA. (2021). Neonatal Jaundice. Sep 16. In: StatPearls [Internet]. Treasure Island (FL): StatPearls Publishing; 2021 Jan. PMID: 30422525.

3. Phang-Lyn S, Llerena VA. (2021). Biochemistry, Biotransformation. 2021 Aug 30. In: StatPearls [Internet]. Treasure Island (FL): StatPearls Publishing; Jan-. PMID: 31335073.

4. Nita M, Grzybowski A (2016). The Role of the Reactive Oxygen Species and Oxidative Stress in the Pathomechanism of the AgeRelated Ocular Diseases and Other Pathologies of the Anterior and Posterior Eye Segments in Adults. Oxid Med Cell Longev. 2016;2016:3164734. doi: 10.1155/2016/3164734. Epub. Jan 10. PMID: 26881021; PMCID: PMC4736974.

5. Zhao RZ, Jiang S, Zhang L, Yu ZB (2019). Mitochondrial electron transport chain, ROS generation and uncoupling (Review). Int J Mol Med.; 44(1):3-15. doi:10.3892/ijmm.2019.4188

6. Xinfeng Chen, Mengjia Song, Bin Zhang, and Yi Zhang (2016). Reactive Oxygen Species Regulate T. Cell Immune Response in the Tumor Microenvironment. Oxidative Medicine and Cellular Longevity. 2016; 2016:1580967. doi: 10.1155/20161580967. PMID: PMC4980531
7. Anastasiya V. Snezhkina, Anna V. Kudryavtseva, Olga L. Kardymon,1 Maria V. Savvateeva , Nataliya V. Melnikova, George S. Krasnov, and Alexey A. Dmitriev (2019). ROS Generation and Antioxidant Defense Systems in Normal and Malignant Cells. Oxidative Medicine and Cellular Longevity. 2019;2019: 6175804. Published 2019 Aug 5. Doi: $10.1155 / 2019 / 6175804$.

8. Schieber M, Chandel NS (2014). ROS function in redox signaling and oxidative stress. Curr Biol.;24 (10):R453-R462. doi:10.1016/j.cub.2014.03.034

9. L Leduc (2019). Solving the opioid epidemic in Ohio, NIH (August 21, 2019)

10. DCFDA / H2DCFDA - Cellular ROS Assay Kit (ab113851), by abcam

11. Wang, Bangchen (2018). "Mechanisms for the Potassium Sparing Effects of Furosemide in Mice on High Potassium Diets" Theses \& Dissertations. 281.

12. Hendry BM, Ellory JC (1988). Molecular sites for diuretic action, Trends Pharmacol Sci, vol. 9

13. Annelies A. van Angelen, AnneMiete W. van der Kemp, Joost G. Hoenderop, René J. Bindels (2012), Increased expression of renal TRPM6 compensates for $\mathrm{Mg} 2+$ wasting during furosemide treatment, Clinical Kidney Journal, Volume 5, Issue 6, December, Pages 535-544.

14. Smith, C., Rogers, L. \& Valentine, C. (1998). Furosemideinduced Oxidant Stresses in mice are Compartmentalized in Hepatic Mitiochondria. Pediatr Res 43, 196.

15. Amini, K., Zhaleh, H., Tahvilian, R., Farnia, V. (2019). Low concentration of morphine protects against cell death, oxidative stress and calcium accumulation by nicotine in PC12 cells. Bratisl Lek. Listy 120 (4), 256-262. doi: 10.4149/BLL_2019_042

16. Zeng Xian-Si, Geng Wen-Shuo, Wang Zhan-Qi, Jia Jin-Jing (2020), Morphine Addiction and Oxidative Stress: The Potential Effects of Thioredoxin-1. Frontiers in Pharmacology, Vol 11 (82).

17. Wang, B., Su, C. J., Liu, T. T., Zhou, Y., Feng, Y., Huang, Y., et al. (2018). The neuroprotection of low-dose morphine in cellular and animal models of parkinson's disease through ameliorating endoplasmic reticulum (ER) stress and activating autophagy. Front. Mol. Neurosci. 11, 120. doi: 10.3389/fnmol.2018.00120

18. Rawat V, Bortolussi G, Gazzin S, Tiribelli C, Muro AF. (2018). Bilirubin-Induced Oxidative Stress Leads to DNA Damage in the Cerebellum of Hyperbilirubinemic Neonatal Mice and Activates DNA Double-Strand Break Repair Pathways in Human Cells. Oxid Med Cell Longev. Nov 26; 2018:1801243. doi: 10.1155/2018/1801243. PMID: 30598724; PMCID: PMC6287157.

19. Murphy M. P. (2009). How mitochondria produce reactive oxygen species. The Biochemical journal, 417(1), 1-13.

20. Katerina Krumova and Gonzalo Cosa (2016). Chapter 1: Overview of Reactive Oxygen Species, in Singlet Oxygen: Applications in Biosciences and Nanosciences, Volume 1, 2016, pp. 1-21 DOI: 10.1039/9781782622208-00001

21. Zorov, D. B., Juhaszova, M., \& Sollott, S. J. (2014). Mitochondrial reactive oxygen species (ROS) and ROS-induced ROS release. Physiological reviews, 94(3), 909-950.

22. Maisels M. J., Gifford K. (1998). Normal Serum Bilirubin Levels in the Newborn and the Effect of Breast-Feeding. Pediatrics Vol 78 (5): 837-843.

23. Watchko, J. Bilirubin Induced Apoptosis In Vitro: Insights for Kernicterus: Commentary on the article by Hank $\varnothing$ et al. on page 179. Pediatr Res 57, 177-178 (2005). 
24. Le Luo, Yutong Yao, Haotian Liao, Jiwei Huang, Mingheng Liao, Jinju Wang, Kefei Yuan, Yong Zeng (2001). Cumulative damage effect of jaundice may be an effective predictor of complications in patients undergoing radical resection of Bismuth type II or above hilar cholangiocarcinoma. Annals of Translational Medicine; Vol 9, No 10 (May 2021).

\section{Supplementary Data Table}

\begin{tabular}{|c|c|c|c|c|c|c|}
\hline \multirow[t]{2}{*}{\begin{tabular}{l|} 
Hour 1 \\
Data \\
Analysis \\
\end{tabular}} & $\begin{array}{l}\text { Background } \\
\text { vs } \\
\text { Furosemide }\end{array}$ & & $\begin{array}{l}\text { Background } \\
\text { vs Morphine }\end{array}$ & & $\begin{array}{l}\text { Background } \\
\text { vs Bilirubin } \\
\end{array}$ & \\
\hline & Background & Furosemide & Background & Morphine & Background & Bilirubin \\
\hline & 1346 & 3537.5 & 1346 & 6661.4 & 1346 & 4994 \\
\hline & 4775 & 6363 & 4775 & 8785 & 4775 & 7278 \\
\hline & 2744 & 5427 & 2744 & 3825 & 2744 & 8260.5 \\
\hline & 6288 & & 6288 & & 6288 & \\
\hline & $\begin{array}{l}\text { Two Tail } \\
\text { Unpaired } \\
\text { Test }\end{array}$ & & $\begin{array}{l}\text { Two Tail } \\
\text { Unpaired T- } \\
\text { Test }\end{array}$ & & $\begin{array}{l}\text { Two Tail } \\
\text { Unpaired T- } \\
\text { Test }\end{array}$ & \\
\hline & $\mathrm{p}=$ & 0.379829335 & $p=$ & 0.21663919 & $p=$ & 0.09060641 \\
\hline $\begin{array}{l}\text { Hour 2 } \\
\text { Data } \\
\text { Analysis } \\
\end{array}$ & $\begin{array}{l}\text { Background } \\
\text { vs } \\
\text { Furosemide }\end{array}$ & & $\begin{array}{l}\text { Background } \\
\text { vs Morphine }\end{array}$ & & $\begin{array}{l}\text { Background } \\
\text { vs Bilirubin }\end{array}$ & \\
\hline & Background & Furosemide & Background & Morphine & Background & Bilirubin \\
\hline & 0 & 0 & 0 & 475 & 0 & 2770 \\
\hline & 0 & 0 & 0 & 0 & 0 & 3792 \\
\hline & 0 & 0 & 0 & 0 & 0 & 4269 \\
\hline & 0 & & 0 & & 0 & \\
\hline & $\begin{array}{lr}\text { Two } & \text { Tail } \\
\text { Unpaired } & \text { T- } \\
\text { Test } & \\
\end{array}$ & & $\begin{array}{lr}\text { Two } & \text { Tail } \\
\text { Unpaired } & \text { T- } \\
\text { Test } & \\
\end{array}$ & & $\begin{array}{lr}\text { Two } & \text { Tail } \\
\text { Unpaired } & \text { T- } \\
\text { Test } & \\
\end{array}$ & \\
\hline & $\mathrm{p}=$ & Uncalculatable & $p=$ & 0.42264973 & $p=$ & 0.01466949 \\
\hline
\end{tabular}

Suppl. Table 1. The data table shows a two-tailed unpaired t-test for the average ROS fluoresce of the background against the average ROS fluorescence of furosemide, bilirubin, and morphine. The unpaired t-test was performed for all three compounds against the background at both Hour 1 and Hour 2 . The p-value is denoted for each corresponding test below the corresponding table and highlighted. A p-value $<0.05$ denotes that the value is of statistical significance when compared to the background. A p-value $>0.05$ denotes a value that is not of statistical significance. During Hour 1 , the $\mathrm{p}$-value of ROS fluorescence of furosemide $(\mathrm{p}=0.3798)$, morphine $(\mathrm{p}=0.2166)$, and bilirubin $(\mathrm{p}=0.0906)$ against the background were greater than .05 and did not display any statistical significance. During Hour 2, the p-value of ROS fluorescence of furosemide was unable to be calculated as no ROS fluorescence was produced. During Hour 2, $\mathrm{p}$-value of ROS fluorescence of morphine $(\mathrm{p}=0.4226)$ against the background was greater than 0.05 and did not display any statistical significance. During Hour 2, p-value of ROS fluorescence of bilirubin ( $\mathrm{p}=0.0147)$ against the background was less than 0.05 , making that the level of ROS fluorescence statistically significant. 
To Submit Your Article Click Here: Submit Manuscript

DOI: $10.31579 / 2641-5194 / 058$
Ready to submit your research? Choose Auctores and benefit from:

$>$ fast, convenient online submission

$>$ rigorous peer review by experienced research in your field

$>$ rapid publication on acceptance

$>$ authors retain copyrights

$>$ unique DOI for all articles

$>$ immediate, unrestricted online access

At Auctores, research is always in progress.

Learn more https://auctoresonline.org/journals/gastroenterologypancreatology-and-hepatobilary-disordersC 